Research Article

\title{
A New Method to Calculate Additional Damping Ratio considering the Effect of Excitation Frequency
}

\author{
Weizhi Xu (D), Dongsheng Du $\mathbb{D}^{\mathbb{D}}$, Shuguang Wang, and Weiwei Li \\ College of Civil Engineering, Nanjing Tech University, Nanjing 211816, China \\ Correspondence should be addressed to Dongsheng Du; ddshy@njtech.edu.cn
}

Received 27 December 2019; Revised 10 July 2020; Accepted 29 July 2020; Published 24 August 2020

Academic Editor: John Mander

Copyright (c) 2020 Weizhi Xu et al. This is an open access article distributed under the Creative Commons Attribution License, which permits unrestricted use, distribution, and reproduction in any medium, provided the original work is properly cited.

\begin{abstract}
The additional damping ratio (ADR) is an important indicator for evaluating the damping effect of structures with energydissipation devices. Most existing methods for determining the ADR require an analysis of the structural dynamic response and complex iterative calculations. An innovative simplified calculation method for determining the ADR of a structure supplemented by nonlinear viscous dampers is proposed. This method does not require the dynamic response of the structure to be calculated and only requires the structural characteristics, excitation frequency, and damper parameters. In this study, several typical calculation methods for the ADR were analysed. Then, a calculation formula for the ADR was derived with consideration of harmonic excitation under the condition where the excitation frequency is equal to the structural natural frequency, without calculation of the structural dynamic response or an iterative process. The effect of the excitation frequency on the calculated value of the ADR with different damping exponents was studied. Accordingly, the response spectrum average period (RSAP) was considered as the excitation period of ground motion to evaluate the excitation frequency, and a simplified calculation method for the ADR considering the effect of the excitation frequency characterised by the RSAP of the ground motion was established. Finally, the accuracy and effectiveness of the proposed method were verified by comparison with ADRs calculated using other methods.
\end{abstract}

\section{Introduction}

In the past two decades, many major earthquakes have occurred in the world, which have caused many casualties and considerable property damage [1-3]. Both structural and nonstructural failures induced by seismic excitation are responsible for the losses. Therefore, it is vital to improve the seismic performance of building structures. The introduction of passive energy-dissipation technology to building structures provides an effective solution to increase the structural damping and mitigate the effect of seismic action, and the importance of damping has been widely recognised in the field of structural dynamics. Effective damping has three main components [4]: inherent damping; supplemental damping provided by the dampers; the hysteretic damping, which is related to the nonlinear behaviour of the structure.

Microscopic internal friction, local plastic deformation, and plastic flow in a range of stresses within the apparent elastic limit account for a major proportion of the energy dissipation due to the inherent damping [5]. In numerical analysis, it is important to select an appropriate inherent damping model. A few damping models have been proposed and widely used in numerical analysis, e.g., viscous damping (VD), Rayleigh damping (RD), mass-proportional damping (MD), and stiffness-proportional damping (SD). The RD model, which consists of MD and SD, is widely used in commercial finite-element platforms because of its mathematical simplicity. Huang [5] reported that the desired energy-dissipation rate was achieved at only two target frequencies and that the mass-proportional term applies damping to rigid-body modes, which cannot dissipate energy in reality. To solve this problem, a versatile frequencyinsensitive damping modelling method was developed, which can achieve approximately uniform energy dissipation in the specified frequency range and make the damping orthogonal to the rigid-body motion. In a few studies [6-8], 
the damping leakage phenomenon in structural systems was investigated, revealing that the damping leakage can result in a significant underestimation of the first-mode response and/or higher-mode responses. To mitigate the problems associated with the improper damping models in the baseisolated structure, Anajafi et al. [6] proposed a damping modelling approach that involves removing the mass-proportional component of superstructure damping from the global damping matrix.

In addition to the inherent damping, the additional damping ratio (ADR), which consists of contributions from various energy-dissipation devices (EDDs), has been utilised in different types of structures to mitigate the structural responses induced by seismic excitation [9-16]. The viscous fluid damper (VFD) - a rate-dependent EDD—is favoured by engineers and increasingly used in engineering structures to reduce excessive vibrations because of the absence of supplemental stiffness and a high energy-dissipation rate in different deformation stages. Wu et al. [17] evaluated the seismic performance of a nine-story steel frame supplemented with five typical dampers under near-fault earthquakes. The results indicated that the VFD functioned better than other four types of dampers even under high pulse velocity amplitude (PVA). To quantitatively evaluate the damping effects for structures supplemented with VFDs, the ADR was proposed. Additionally, in China, the ADR is a key structural parameter for engineers in the design process. Firstly, the target ADR is determined; then, the aseismic design is conducted via the mode analysis response spectrum method, considering the total damping ratio, the sum of the inherent damping ratio, and the ADR. Subsequently, the damper parameters and the layout are designed to achieve the target ADR. The design process determines the importance of estimating the ADR of the structures equipped with EDDs.

Recently, scholars have proposed various calculation methods for the ADR. Lee et al. [18] proposed an evaluation method for the equivalent damping ratio for systems configured with dampers. In that study, the Lyapunov function was first defined in the form of the modal energy; then, the Riccati matrix and damping ratio parameters were derived. Finally, a formula for the equivalent damping ratio was obtained by analogising the viscous modal damping ratio. Charney et al. [19] used the modal strain energy method, free vibration logarithmic decay method, and eigenvector method for complex eigenvalues to analyse the equivalent VD ratio of a single-story, single-bay frame. The results indicated that higher flexibility of the nodes corresponded to a larger phase difference between the deformation velocity and the relative horizontal velocity of the interlayer devices. However, this conclusion was only applicable to the singlelayer, single-span structure. Occhiuzzi et al. [20] proposed a method for calculating the modal damping ratio using an equation for the dynamic system state. An analysis revealed that the first vibration mode significantly affected the damping ratio, whereas the effects of the higher-order vibration modes were negligible. The aforementioned calculation methods, which involve complex theoretical formulas and large amounts of calculations, are difficult for engineers to apply. Therefore, a simpler, direct method needs to be developed.

Silvestri et al. [21-23] proposed a practical method for the aseismic design of structures configured with VFDs, in which the mechanical characteristics of the VFDs are easily determined according to the performance objectives of the structure. However, the calculation method adopted for the ADR still cannot be widely used in practical engineering. Diotallevi et al. [24] proposed a method for evaluating the ADR according to the damping index. This method has the advantage of realising direct evaluation of ADR without iteration but is limited to the evaluation of linear-elastic systems. Weng et al. [25] proposed a method for calculating the equivalent $\mathrm{ADR}$ of the viscous damper according to the code response spectrum. Landi et al. [26] proposed a simplified method for calculating the ADR according to the capability and demand spectra. Under the condition of confirmed yield acceleration and target displacement of the known structure, the corresponding ductility factor, equivalent total damping ratio, and significant period could be confirmed directly. Kudu et al. [27] compared the modal damping ratios determined with consideration of the measurement time, frequency scope, and sample rate. When the modal damping ratio changed significantly, the natural frequency of the structure did not. Ishimaru et al. [28] presented an approach for calculating the optimal VD ratio and accumulated ductility of a structure configured with a bilinear hysteretic damper and a dynamic quality damper, which has a very high accuracy for calculating the accumulated ductility coefficient. A method for calculating the ADR based on the concept of effective modal damping energy dissipation was proposed by Weng et al. [29], which has a clear physical significance and fully considers the timevarying characteristics of the effective damping ratio. Its advantages include simple calculations and a high accuracy. Landi et al. [30] performed probabilistic seismic assessment of RC structures with and without a damper using a simplified SAC Federal Emergency Management Agency (SACFEMA) program. The results showed that the method was effective and could be used as a simplified alternative to nonlinear dynamic analyses for probabilistic assessment purposes. Love and Tait [31] proposed a simple method for predicting the effective damping of a linear structure with nonlinear EDDs. This method exploits the characteristic that the output mean energy of the structure remains unchanged under a wind load to make predictions. However, the error between the prediction results of this method and the calculation results based on time-history analysis was significant. He et al. [32] proposed an effective finite-element analysis method for calculating the modal damping ratio of complex materials and proved the effectiveness and accuracy of the method through a theoretical analysis and a comparison with experimental results.

Most of the aforementioned methods for calculating the ADR require the calculation of the structural dynamic response and iteration, making them cumbersome and inconvenient to use directly in practical engineering. Additionally, the solutions of the ADR for supplemental nonlinear VFDs based on the energy principle rarely 
consider the effect of the excitation frequency on the ADR. Hence, it is necessary to establish a calculation method for the ADR that reflects the effect of the excitation frequency on the dynamic response of the structure with VFDs.

The remainder of this paper is organised as follows. Section 2 introduces two typical calculation methods for the ADR: the energy-ratio method (ERM) and the damping index method (DIM). Section 3 presents the proposed method for calculating the ADR under harmonic excitation considering the impact of the excitation frequency, which is theoretically derived. Then, the response spectrum average period (RSAP) is used to distinguish the frequency properties of different ground motions. Subsequently, a simplified calculation method for the ADR under ground motion is presented. In Section 4, the accuracy and effectiveness of the proposed calculation method for the ADR are confirmed through a case study. Conclusions and directions for improvement of the proposed method are presented in Section 5.

\section{Existing Methods for Calculating ADR}

2.1. ERM. Chopra [33] proposed a classical calculation equation for the ADR based on the principle of hysteresis energy equivalence:

$$
\zeta_{\text {sd }}=\frac{w_{D}}{4 \pi w_{S o}} \frac{\omega}{\Omega},
$$

where $w_{S o}$ represents the maximum strain energy of the damping structure with a viscous damper under the expected displacement, $w_{D}$ represents the energy consumed by the viscous damper in one cycle with the expected deformation, and $\omega$ and $\Omega$ represent the structural natural frequency and the excitation frequency, respectively.

The damping force is given as follows:

$$
F_{D}=c_{\alpha} \operatorname{sgn}(\dot{u})|\dot{u}|^{\alpha},
$$

where $c_{\alpha}$ is the damping coefficient corresponding to different velocity exponent $(\alpha)$ values and sgn $(x)$ is a sign function.

For a single-degree-of-freedom (SDOF) system subjected to a harmonic displacement excitation with the function of $u(t)=u_{0} \sin \Omega \mathrm{t}$, the energy consumption of the nonlinear viscous damper is given as follows:

$$
w_{D}=\int F_{\mathrm{D}} \mathrm{d} u=\int_{0}^{2 \pi / \Omega} c_{\alpha}|\dot{u}|^{1+\alpha} \mathrm{d} t .
$$

Integration of equation (3) yields

$$
w_{D}=\lambda c_{\alpha} u_{0}^{1+\alpha} \Omega^{\alpha},
$$

where $\lambda$ is a constant related to $\alpha$.

When $\alpha=1, \lambda=\pi$, and the following equation can be obtained:

$$
w_{D}=\pi c_{1} u_{0}^{2} \Omega
$$

Linearisation of the nonlinear viscous damper is performed according to the equal dissipating energy of a linear viscous damper, and the equivalent linear damping coefficient $c_{1}$ can be determined using the following equation:

$$
\pi c_{1} u_{0}^{2} \Omega=\lambda c_{\alpha} u_{0}^{1+\alpha} \Omega^{\alpha} .
$$

By dividing both sides of equation (6) by $2 m \omega$, the ADR of nonlinear viscous dampers can be calculated as follows:

$$
\zeta_{\mathrm{sd}}=\frac{\lambda}{\pi} \frac{c_{\alpha}}{2 m \omega} \frac{1}{\left(\Omega u_{o}\right)^{1-\alpha}},
$$

where $m$ represents the mass of the structure.

This classical method is easy to understand. However, the structural dynamic response must be calculated to determine the maximum displacement, and the calculation process is complex, which is not convenient for practical engineering.

2.2. DIM. To overcome the shortcomings of the ERM, Landi [25] proposed a method for evaluating the ADR directly according to the damping index. For an SDOF system under harmonic excitation, the damping index $\varepsilon$ is defined by the following relationship:

$$
\varepsilon=\frac{\lambda}{\pi} \frac{c_{\alpha}}{2 m} \frac{\omega^{1-2 \alpha}}{\Omega^{1-\alpha}} a_{0}^{\alpha-1},
$$

where $a_{0}$ represents the peak acceleration of harmonic excitation.

Under the resonance condition, i.e., $\Omega=\omega$, equations (7) and (8) can be rewritten as follows:

$$
\begin{aligned}
\zeta_{\mathrm{sd}} & =\frac{\lambda}{\pi} \frac{c_{\alpha}}{2 m \omega^{2-\alpha}} \frac{1}{\left(u_{o}\right)^{1-\alpha}}, \\
\varepsilon & =\frac{\lambda}{\pi} \frac{c_{\alpha}}{2 m} \frac{1}{\omega^{\alpha}}\left(\ddot{u}_{g 0}\right)^{\alpha-1},
\end{aligned}
$$

respectively, where $\ddot{u}_{g 0}$ represents the peak acceleration of the seismic excitation.

The relationship between ADR $\zeta_{\text {sd }}$ and the damping index $\varepsilon$ can be expressed as follows:

$$
\zeta_{\mathrm{sd}}=\varepsilon R_{d}^{\alpha-1}
$$

where $R_{d}=\left(\omega^{2} u_{0} / \ddot{u}_{g 0}\right)$, reflecting the amplification of the dynamic response.

The acceleration amplification factor $R_{a}$ can be computed via numerical analysis, and the damping index $\varepsilon$ can be determined according to the structural and input characteristics. Then, ADR $\zeta_{\text {sd }}$ is calculated using equation (11). Figure 1 shows the ADR-frequency ratio curves with different damping indices $(\varepsilon)$ and $\alpha=0.50$ under harmonic excitation, and Figure 2 shows the ADR spectra for different damping indices $(\varepsilon)$ and $\alpha=0.50$ under the El Centro ground motion recorded during the Imperial Valley Earthquake on May 18, 1940. According to the curves in Figures 1 and 2, $\mathrm{ADR} \zeta_{\mathrm{sd}}$ is directly obtained when the damping index $\varepsilon$ and frequency ratio $(\Omega / \omega)$ or natural period $(T)$ of the structure 


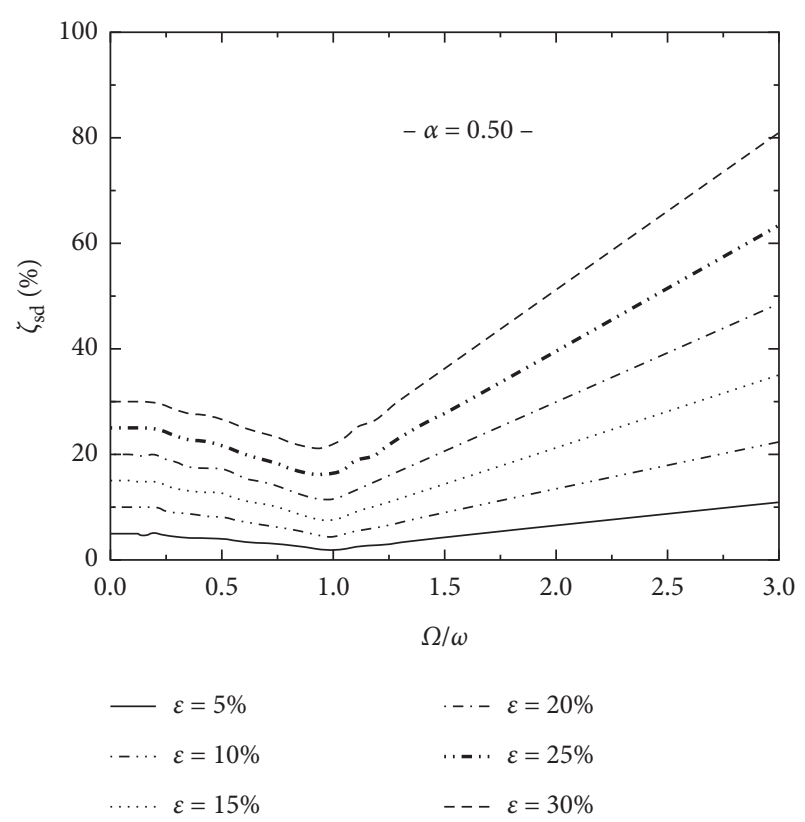

FIGURE 1: Relationship between the ADR and the frequency ratio for different damping indices $(\varepsilon)$ under harmonic excitation.

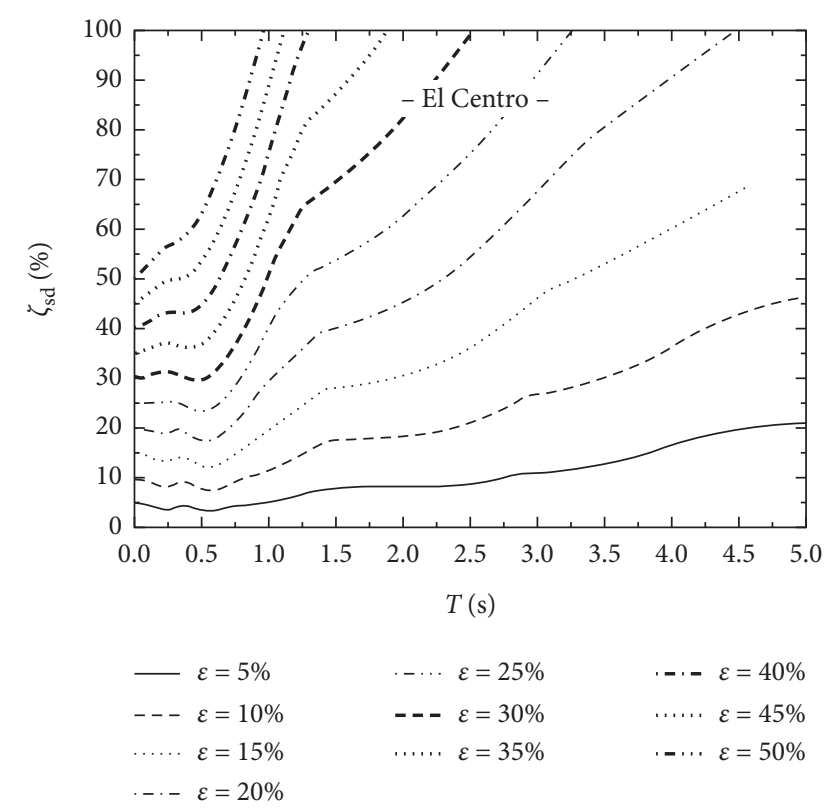

FIGURE 2: ADR spectra for different values of $\varepsilon$ under the excitation of the north-south component of El Centro ground motion $(\alpha=0.50)$.

are determined. It appears that the ADR can be determined directly, without calculation of the structural response. Figures 1 and 2 were obtained via numerical analysis of the structure with additional dampers.

\section{New Simplified Calculation Method for ADR}

To calculate the ADR of a structure equipped with nonlinear viscous dampers more conveniently, a simplified method is proposed on the basis of the foregoing methods. In the proposed method, the structural response need not be calculated; rather, only the spectral characteristics of ground motions must be considered.

3.1. ADR of Damping System under Harmonic Excitation. The dynamic equation of the SDOF system with a linear damper under harmonic excitation is

$$
m \ddot{u}+c_{1} \dot{u}+k u=a_{0} m \sin \Omega t,
$$

where $c_{1}$ is the damping coefficient of the linear viscous damper when the structural damping is 0 and $a_{0}$ represents the peak acceleration of harmonic excitation.

The complete solution of equation (12) [33] is

$$
" u(t)=e^{-\xi_{1} \omega t}\left(A \cos \omega_{D} t+B \sin \omega_{D} t\right)+(C \sin \Omega t+D \cos \Omega t),
$$

where $\omega_{D}=\omega \sqrt{1-\zeta_{1}^{2}}$ represents the frequency of the structure considering damping, $\omega$ represents the natural frequency of the structure, and $\zeta_{1}$ represents the damping ratio of the linear viscous damper.

Considering the initial conditions $u(0)=0$ and $\dot{u}(0)=0$, the following can be obtained:

$$
\begin{aligned}
& C\left(\zeta_{1}, \frac{\Omega}{\omega}\right)=\frac{a_{0}}{\omega^{2}} \frac{1-(\Omega / \omega)^{2}}{\left[1-(\Omega / \omega)^{2}\right]^{2}+\left[2 \zeta_{1}(\Omega / \omega)^{2}\right]^{2}}, \\
& D\left(\zeta_{1}, \frac{\Omega}{\omega}\right)=\frac{a_{0}}{\omega^{2}} \frac{-2 \zeta(\Omega / \omega)}{\left[1-(\Omega / \omega)^{2}\right]^{2}+\left[2 \zeta_{1}(\Omega / \omega)\right]^{2}} .
\end{aligned}
$$

According to equation (13), the steady-state dynamic response $u_{s}$ is calculated as follows:

$$
u_{s}=u_{s 0} \sin (\Omega t+\varphi) \text {, }
$$

where $u_{s 0}=\sqrt{C^{2}+D^{2}}$ and $\tan (\varphi)=D / C$.

The steady-state response is taken as the approximate response of the structure, i.e.,

$$
u_{0}=u_{s 0}
$$

Considering the equal energy consumption of linear and nonlinear dampers and the identical peak dynamic responses of the SDOF for linear and nonlinear dampers, the ADRs of the two damping systems should be equal:

$$
\zeta_{1}=\zeta_{s d}
$$

According to equations (7), (16), and (17), the ADR can be determined as follows:

$$
\zeta_{\text {sd }}=\frac{\lambda}{\pi} \frac{c_{\alpha}}{2 m \omega} \frac{1}{\left(\Omega \sqrt{C^{2}+D^{2}}\right)^{1-\alpha}} .
$$

The ADR can be easily determined using equation (18) without calculating the response of the damping structure but with iterative calculations. Comparisons of the ADRs calculated using equation (18) and the ERM are presented in Figures 3 and 4 . As shown, when the frequency ratio $\Omega / \omega$ 


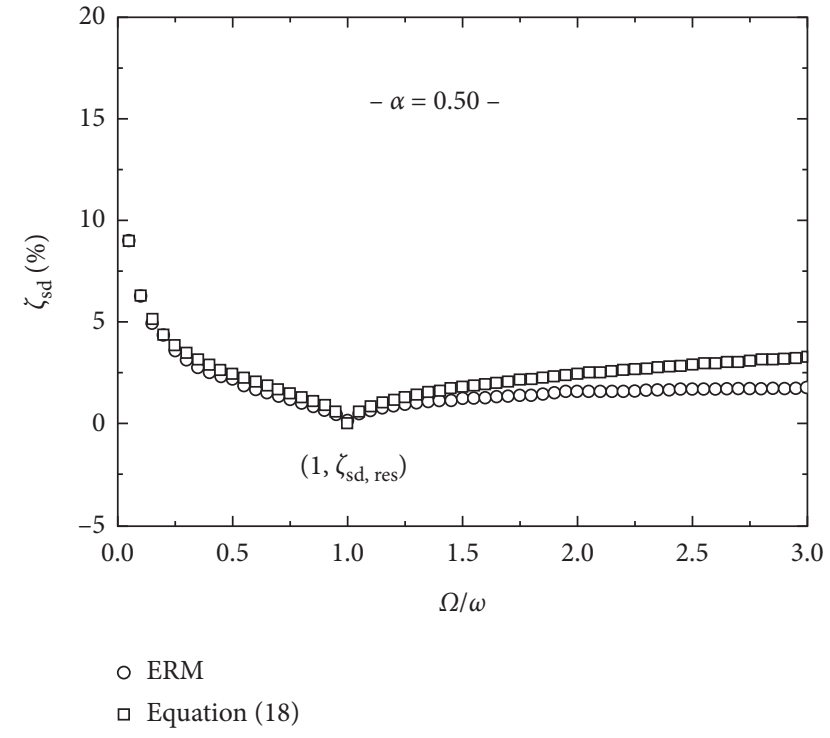

FIgURE 3: Comparison of the ADRs calculated using the two methods with different frequency ratios $(\alpha=0.50)$.

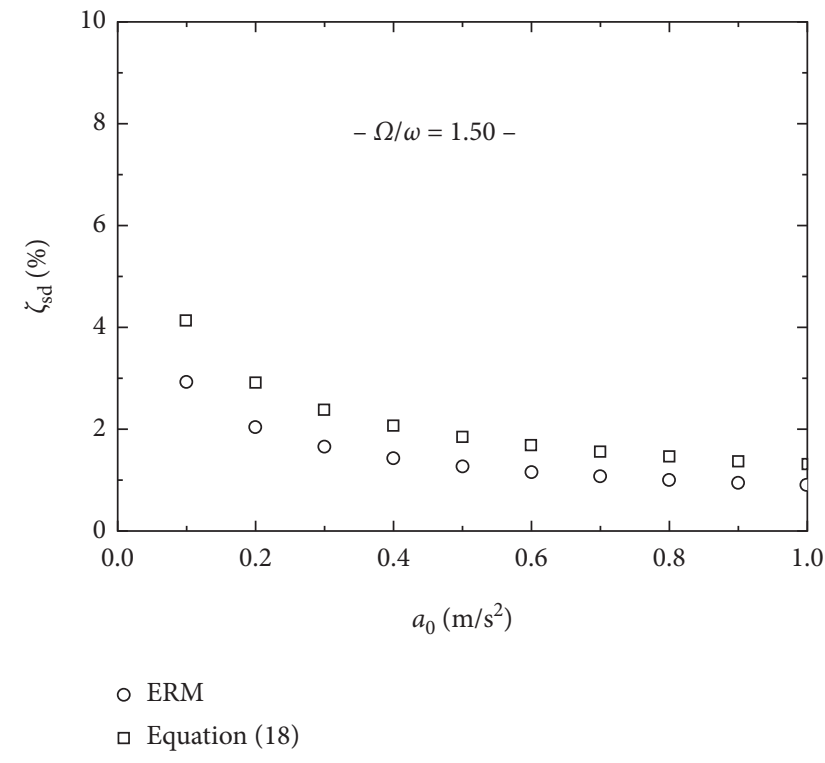

FIgURE 4: Comparison of the ADRs calculated using the two methods with different excitation amplitudes $(\Omega / \omega=1.50)$.

was $\leq 1$, the calculation results of equation (18) agreed well with the results obtained using the ERM; when the frequency ratio was $>1$, the calculation results of equation (18) were larger than those of the ERM owing to the impact of the transient-state solution on the structural response, indicating that the frequency ratio affected the difference between the ADRs calculated using equation (18) and the ERM.

Using equation (18), the ADR can be determined without calculating the dynamic response, but iterative calculations are required. Considering that the results obtained via the two calculation methods are similar, particularly when $\Omega=\omega$, further analysis is conducted for the resonance condition.
When $\Omega=\omega$, equation (15) is simplified as follows:

$$
u_{s 0}=\frac{a_{0}}{2 \omega^{2} \zeta_{1}} \text {. }
$$

Substituting equation (19) into equation (6) and setting $\zeta_{1}=c_{1} / 2 \omega \mathrm{m}$ yields

$$
c_{1}=\left[\frac{\lambda}{\pi}\left(\frac{1}{a_{0} m}\right)^{1-\alpha} c_{\alpha}\right]^{1 / \alpha} .
$$

Then, by dividing both sides of equation (6) by $2 \mathrm{~m} \omega$, the ADR under the resonance condition is obtained:

$$
\zeta_{\text {sd,res }}=\frac{1}{2 m \omega}\left[\frac{\lambda}{\pi}\left(\frac{1}{a_{0} m}\right)^{1-\alpha} c_{\alpha}\right]^{1 / \alpha} .
$$

Figure 5 presents the relationship curves of $\zeta_{\text {sd,res }}$ and $a_{0}$ for different values of $\alpha$ and $c_{\alpha}$. As shown, the calculation results of the two methods agreed well, and the difference between them decreased with the increasing damping exponent. Additionally, the ADR increased with the damping coefficient, owing to the considerable energy dissipation.

\subsection{Simplified Calculation of ADR considering Excitation} Spectral Characteristics. Because of the difference between the ADRs calculated using equation (18) and the ERM depended on the frequency ratio, it was important to study the variation of the ADR with different frequency ratios. Figure 6 shows the curves for the relationship between $\zeta_{\text {sd }}$ and $\Omega / \omega$ obtained via the ERM.

In Figure 6, the ADRs on the left and right sides of the resonance point exhibit different trends, and the curve is approximately parabolic when $\Omega / \omega<1$ and approximately linear when $\Omega / \omega>1$. Therefore, the $\zeta_{\text {sd }}$ vs. $\Omega / \omega$ curve can be defined as a piecewise function containing the structural resonance point $\left(1, \zeta_{\mathrm{sd}, \mathrm{res}}\right)$ as follows:

$$
\zeta_{\text {sd }}= \begin{cases}a_{1}\left(\frac{\Omega}{\omega-1}\right)^{2}+\zeta_{\text {sd,res }}, & \frac{\Omega}{\omega}<1, \\ \zeta_{\text {sd,res }}, & \frac{\Omega}{\omega}=1, \\ a_{2}\left(\frac{\Omega}{\omega-1}\right)+\zeta_{\text {sd,res }}, & \frac{\Omega}{\omega}>1,\end{cases}
$$

where $a_{1}$ and $a_{2}$ are the coefficients that must be determined via fitting.

Figures 7 and 8 present the curves of $a_{1}$ and $a_{2}$ under different damping exponents $(\alpha)$. Numerical fitting revealed that

$$
a_{1}=\beta_{1} e^{\gamma_{1} \alpha},
$$

where $\beta 1=109.6$ and $\gamma 1=-5.489$, and

$$
a_{2}=\beta_{2} e^{\gamma_{2} \alpha},
$$

where $\beta 2=10.02$ and $\gamma 2=-4.649$. 


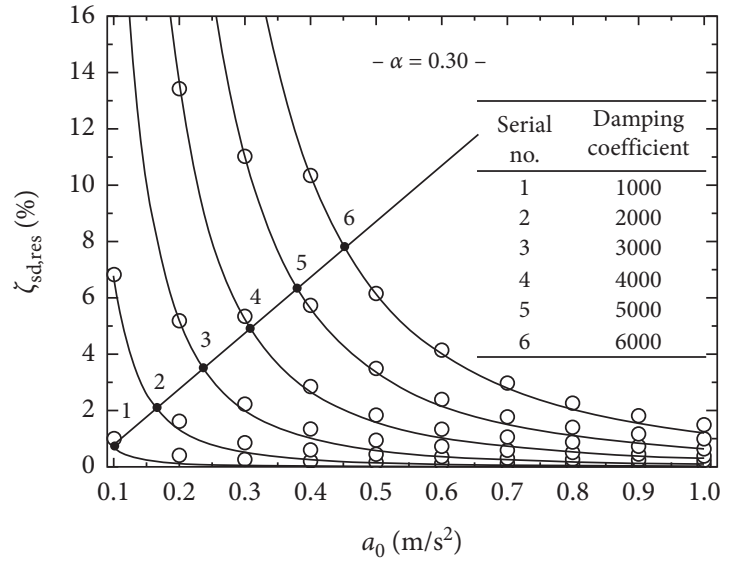

O ERM

— Equation (21)

(a)

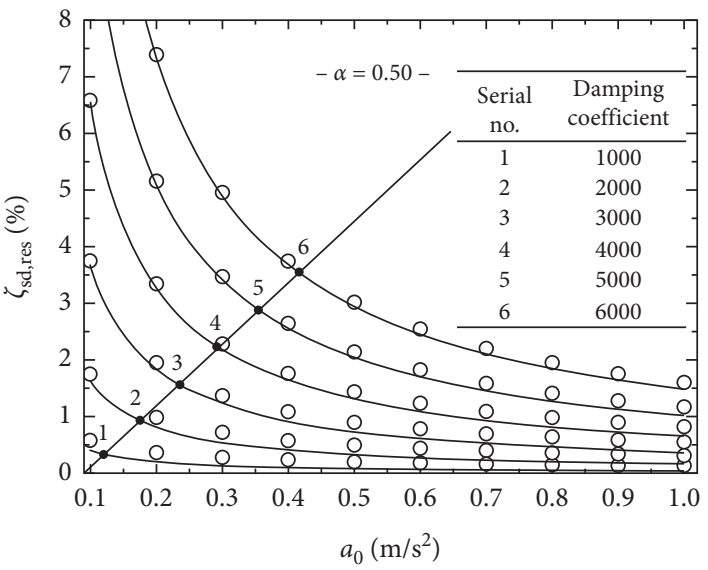

O ERM

— Equation (21)

(c)

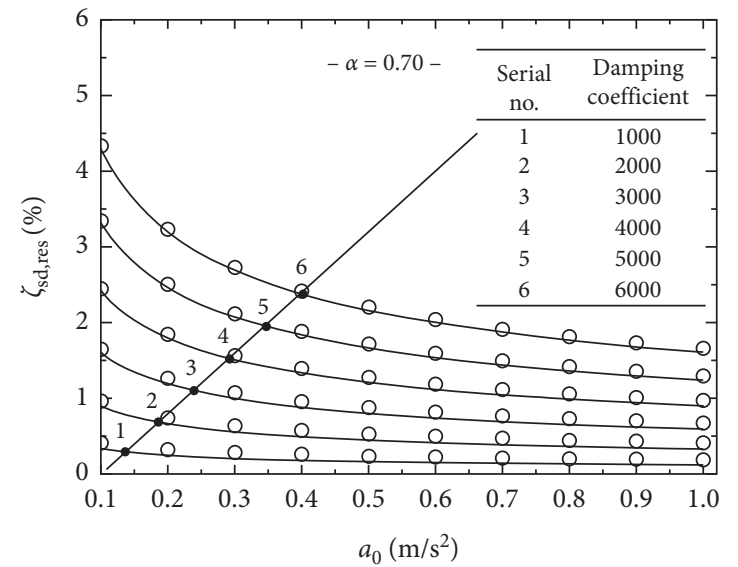

O ERM

- Equation (21)

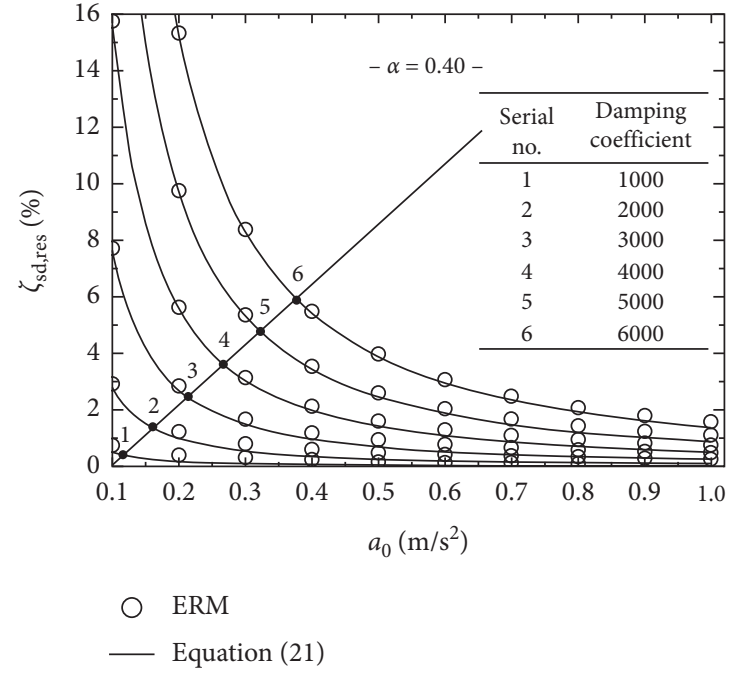

(b)

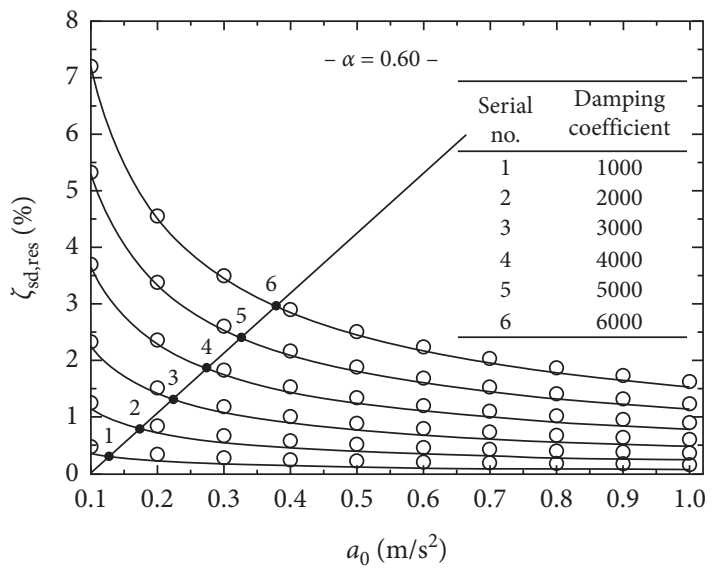

O ERM

— Equation (21)

(d)

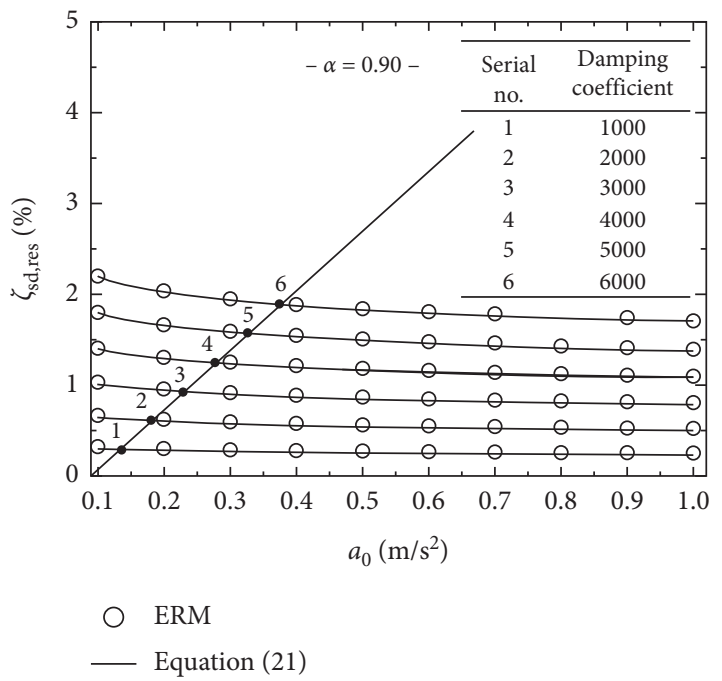

(f)

FIgURe 5: ADRs calculated using the two methods for $c_{\alpha}=1000,2000,3000,4000,5000$, and $6000 \mathrm{kN} \mathrm{s} / \mathrm{m}$ : (a) $\alpha=0.30$; (b) $\alpha=0.40$; (c) $\alpha=0.50$; (d) $\alpha=0.60$; (e) $\alpha=0.70$; (f) $\alpha=0.90$. 


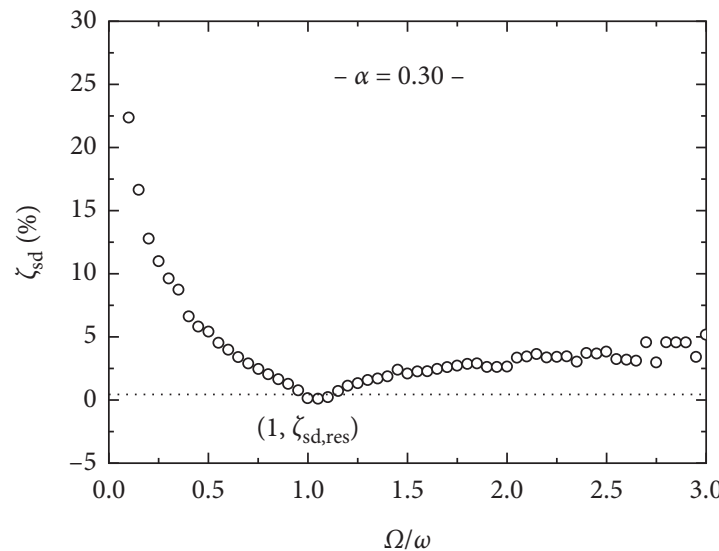

- ERM

(a)

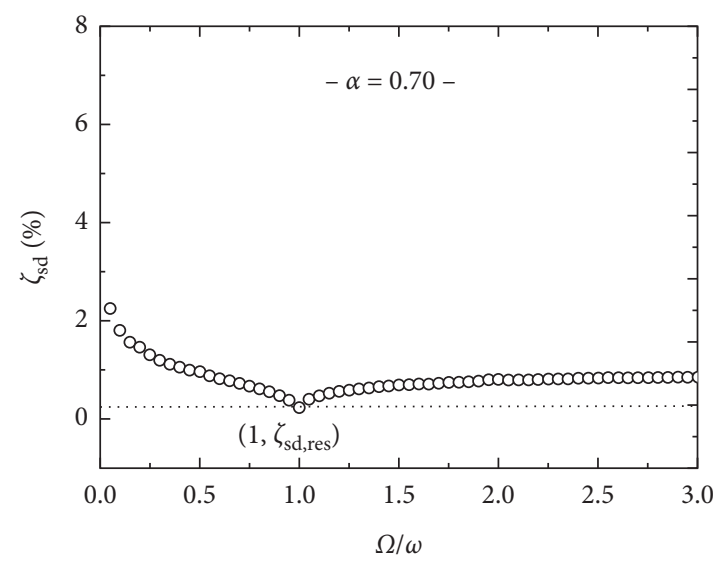

- ERM

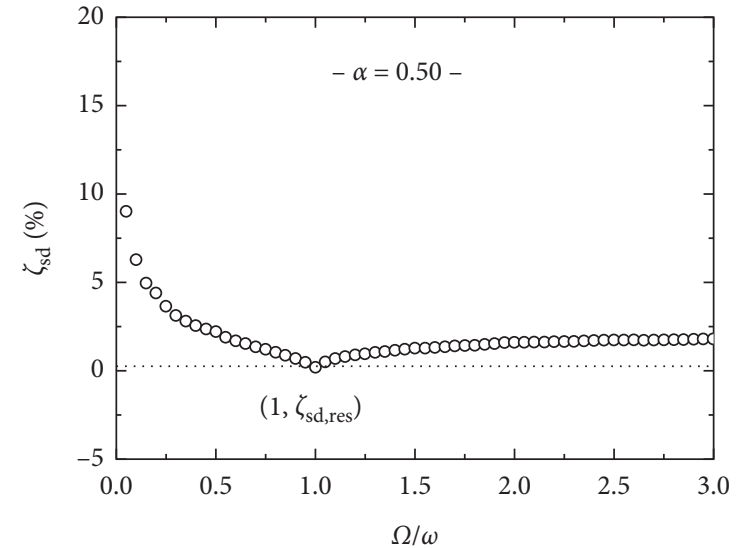

- ERM

(b)

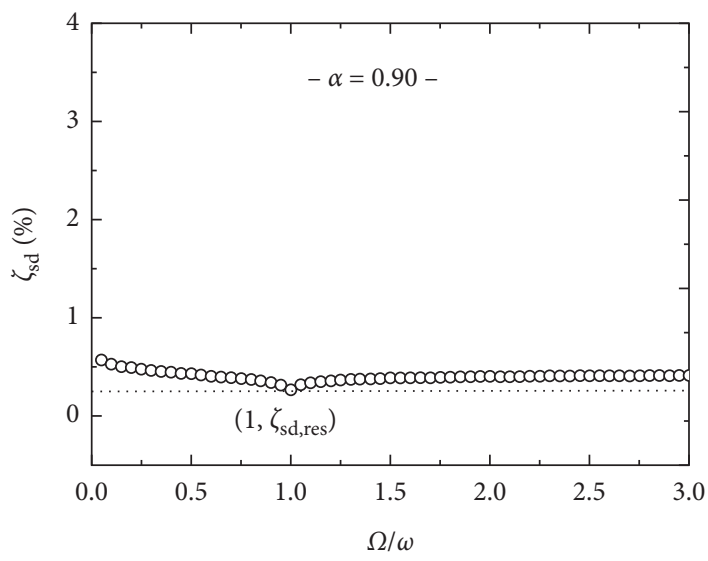

- ERM

(c)

(d)

FIGURE 6: Relationship between ADR $\zeta_{\text {sd }}$ and the frequency ratio $\Omega / \omega$ : (a) $\alpha=0.30$; (b) $\alpha=0.50$; (c) $\alpha=0.70$; (d) $\alpha=0.90$.

Equation (22) was used to determine the ADR after considering the excitation spectral characteristic without calculating the structural dynamic response. Figure 9 presents the relationship curve between $\zeta_{\text {sd }}$ and $\Omega / \omega$ under different damping exponents $(\alpha)$. The calculation results of the ERM, equation (18), and equation (22) are compared. As shown, the calculation results of equation (18) were the largest among the three calculation methods when $\Omega / \omega>1$; however, the calculation results of equation (22) and the ERM agreed well, with sufficient precision for practical engineering.

\subsection{Calculation of ADR of Damping Structure under Ground} Motion Excitation. The spectral characteristics of ground motions affect the structural dynamic response, as well as the ADR. However, the foregoing simplified methods do not consider the impact of the ground vibration frequency on the ADR. Thus, a calculation method for the ADR that does not require calculation of the structural dynamic response but considers the spectral characteristics of the ground motions is derived.
Considering the condition of structural resonance under harmonic excitation, $u_{0}$ is similar to $a_{0} / 2 \omega 2 \zeta$. If

$$
u_{w}=\frac{\ddot{u}_{g 0}}{2 \omega^{2} \zeta},
$$

where $u_{w}$ represents the assumed value of the peak displacement response, which is related to the peak ground acceleration (PGA). There is a relationship between $u_{0}$ and $u_{w}$. The ratio between them is defined as $f_{1}=u_{0} / u_{w}$ and reflects the displacement amplification between the nonresonant and resonant responses of the structure.

Then, $u_{0}$ is determined as follows:

$$
u_{0}=\frac{f_{1} \cdot \ddot{u}_{g 0}}{2 \omega^{2} \zeta_{1}},
$$

where $\ddot{u}_{g 0}$ represents the seismic-excitation peak acceleration and $\zeta_{1}$ represents the ADR of the linear viscous damper.

For a linear structural system subjected to a seismic excitation, the coefficient $f_{1}$ is unrelated to the PGA but is 


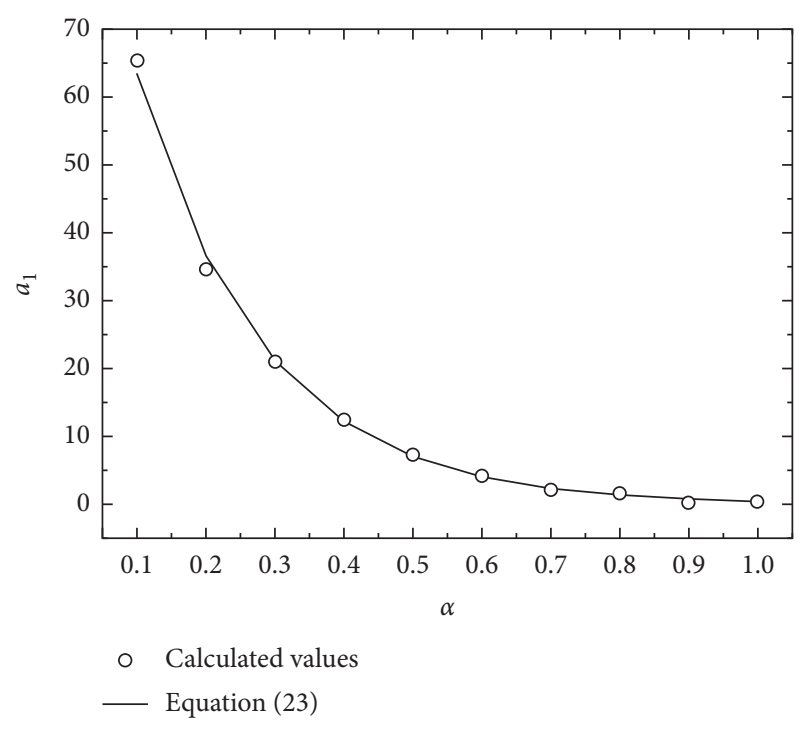

Figure 7: Fitting curve of $a_{1}$.

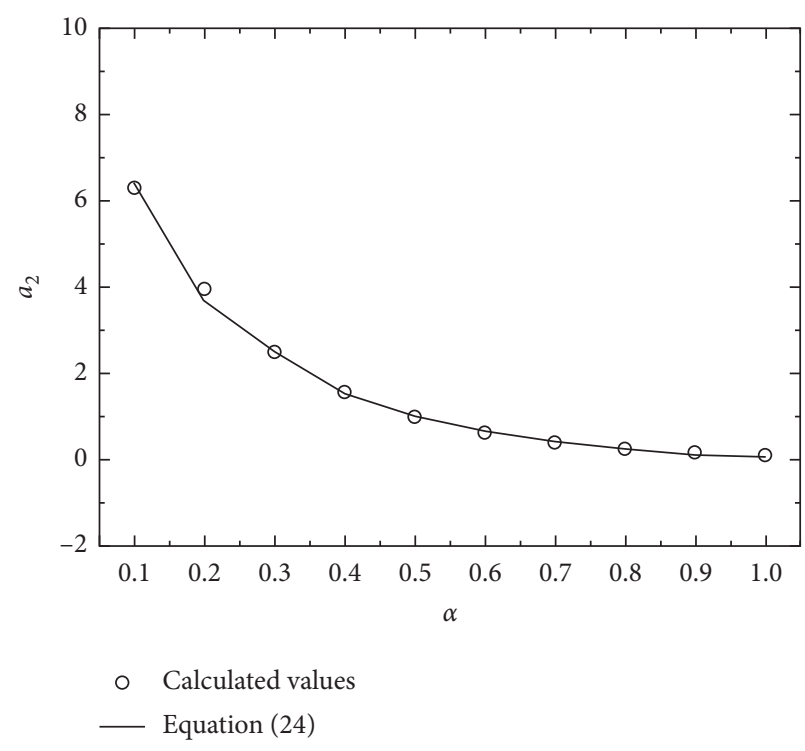

Figure 8: Fitting curve of $a_{2}$.

related to $\operatorname{ADR}\left(\zeta_{1}\right)$. Therefore, $f_{1}$ is designated as a unary polynomial of $\zeta_{1}$ :

$$
f_{1}\left(\zeta_{1}\right)=b_{1} \zeta_{1}^{3}+b_{2} \zeta_{1}^{2}+b_{3} \zeta_{1}+b_{4}
$$

where $b_{1}, b_{2}, b_{3}$, and $b_{4}$ are the coefficients of the polynomial, which can be determined via fitting. The ADR of the structure is typically $<0.5$, thus considering a cubic polynomial can ensure an appropriate accuracy.

Considering the different natural cycle frequencies $(\omega)$ of the structure, a series of coordinate points $\left(\zeta_{1}, f_{1}\right)$ can be obtained through time-history analyses of the SDOF system with different ADRs $\left(\zeta_{1}\right)$. Taking the El Centro seismic record of the Imperial Valley earthquake as an example, considering the different natural cycle frequencies of the structure, $\zeta_{1}$ and corresponding $f_{1}$ values can be obtained, as shown in Figure 10. Table 1 presents the fitting coefficients for the unary polynomial of $\zeta_{1}$. The fitting coefficients with $\omega=5.39$ are used in the case study in Section 4.

By substituting equation (26) into equation (9), the ADR with $\Omega=\omega$ is obtained:

$$
\zeta_{\mathrm{sd}, \mathrm{res}}=\frac{\lambda}{\pi} \frac{c_{\alpha}}{2 m \omega^{2-\alpha}} \frac{1}{\left(f_{1} \ddot{u}_{g 0} / 2 \omega^{2} \zeta_{1}\right)^{1-\alpha}} .
$$

According to equation (17), equation (28) can be transformed into

$$
\zeta_{\text {sd,res }}=\frac{\lambda}{\pi} \frac{c_{\alpha}}{2 m \omega^{2-\alpha}} \frac{1}{\left(f_{1} \ddot{u}_{g 0} / 2 \omega^{2} \zeta_{\text {sd,res }}\right)^{1-\alpha}} .
$$

Equation (22) is used to determine the ADR when $\Omega \neq \omega$ :

$$
\zeta_{\mathrm{sd}}= \begin{cases}a_{1}\left(\frac{\Omega_{m}}{\omega-1}\right)^{2}+\zeta_{\mathrm{sd}, \mathrm{res}}, & \frac{\Omega_{m}}{\omega}<1, \\ \zeta_{\mathrm{sd}, \mathrm{res}}, & \frac{\Omega_{m}}{\omega}=1, \\ a_{2}\left(\frac{\Omega_{m}}{\omega-1}\right)+\zeta_{\mathrm{sd}, \mathrm{res}}, & \frac{\Omega_{m}}{\omega}>1,\end{cases}
$$

where $\Omega_{\mathrm{m}}$ represents the average frequency of the seismic excitation.

The average period $T_{m}$ of a seismic wave can be calculated as follows [29]:

$$
T_{m}=\frac{\sum_{i} C_{i}^{2}\left(1 / F_{i}\right)}{\sum_{i} C_{i}^{2}}
$$

where $C_{i}$ is the Fourier peak coefficient and $F_{i}$ represents the discrete frequency of the fast Fourier transform.

Then average frequency $\Omega_{\mathrm{m}}$ of the seismic input ground motion acceleration is calculated as follows:

$$
\Omega_{m}=\frac{2 \pi}{T_{m}} .
$$

Figures 11 and 12 present the curves of $\mathrm{ADR}\left(\zeta_{\mathrm{sd}}\right)$ vs. the natural vibration period of the structure $(T)$ and the PGA $\left(\ddot{u}_{g 0}\right)$ with different damping coefficients $\left(c_{a}\right.$, in $\left.\mathrm{kN} \cdot \mathrm{s} / \mathrm{m}\right)$ for the El Centro ground motion obtained using the ERM and equations (29) and (30). Here, the damping exponent was $\alpha=0.50$.

As shown in the figures, for $\Omega=\omega$, the calculation results of equation (29) and the ERM agreed well, and for $\Omega \neq \omega$, the calculation results of equation (30) were larger than the calculation results of the ERM. The calculation results of equation (30) were more accurate than those of the equation (29) because this equation considered the impact of the ground motion frequency, and the change law before and after the resonance point was consistent with that under harmonic excitation. 

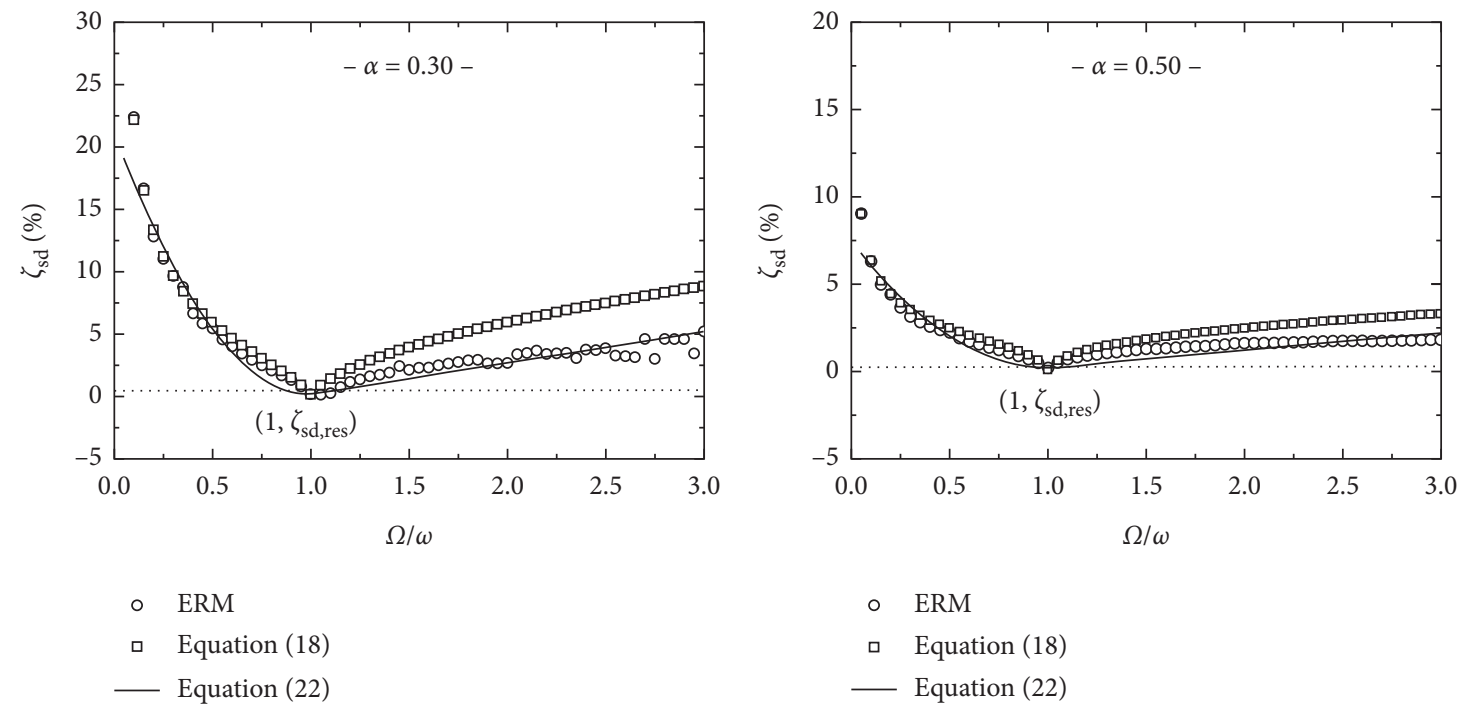

(a)

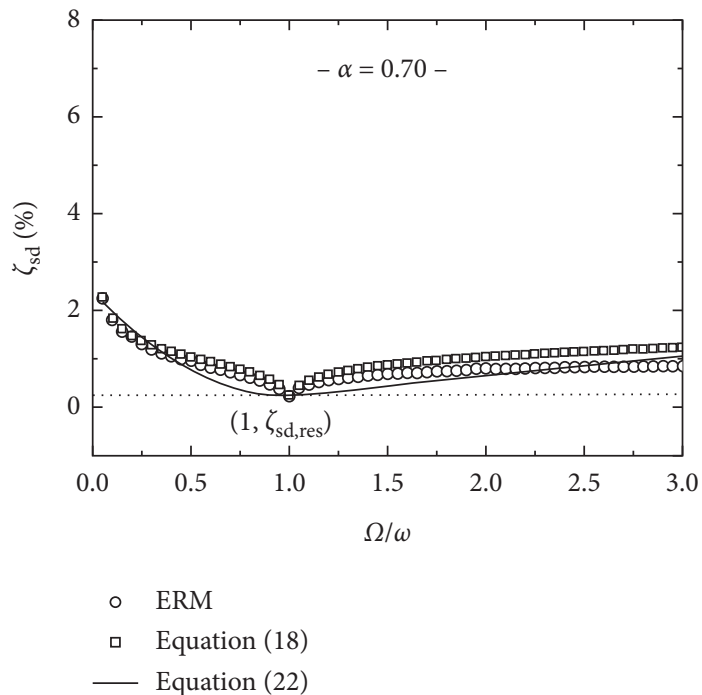

(c)

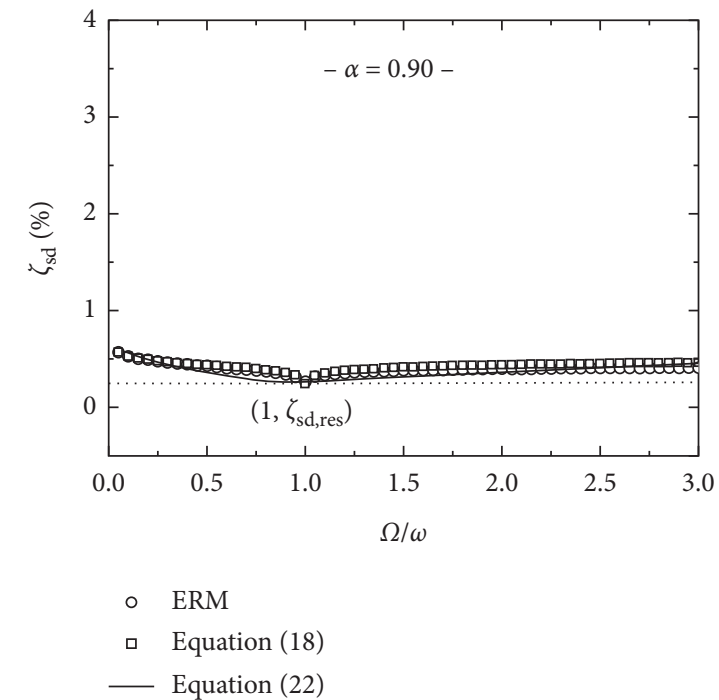

(d)

Figure 9: $\operatorname{ADR}\left(\zeta_{\text {sd }}\right)$ vs. frequency ratio $(\Omega / \omega)$ : (a) $\alpha=0.30$; (b) $\alpha=0.50$; (c) $\alpha=0.70$; (d) $\alpha=0.90$.

\section{Case Study}

In 1997, Takewaki [34] presented an optimal vibration-reduction design for a six-story shear frame (Figure 13). The mass was identical for all the floors of the frame, i.e., $m 1=m 2=\ldots=m 6=0.80 \times 105 \mathrm{~kg}$, and the lateral stiffness was evenly distributed, i.e., $k 1=k 2=\ldots=k 6=4.00 \times 107 \mathrm{~N} /$ $\mathrm{m}$. The initial damping coefficient of each VFD was $c_{1}=1.50 \times 106(\mathrm{~N} \mathrm{~s} / \mathrm{m})$, and the inherent structural damping ratio was taken as $\zeta_{0}=0.05$.

According to the foregoing conditions, it is easy to determine the natural period $T_{1}=1.1656 \mathrm{~s}$ and the first vibration mode of the structure $\{\phi\} T=\{0.2411,0.4681,0.6680$, $0.8290,0.9419,1.0000\}$. According to the equivalent SDOF method [33], the equivalent mass $M^{r}$, equivalent stiffness $K^{r}$, and equivalent damping $C^{r}$ can be obtained as follows:

$$
\begin{aligned}
& M^{r}=\{\phi\}^{T}[M]\{\phi\} \frac{\{\phi\}^{T}[M]\{1\}}{\{\phi\}^{T}[M]\{\phi\}}, \\
& C^{r}=\{\phi\}^{T}[C]\{\phi\} \frac{\{\phi\}^{T}[M]\{1\}}{\{\phi\}^{T}[M]\{\phi\}}, \\
& K^{r}=\{\phi\}^{T}[K]\{\phi\} \frac{\{\phi\}^{T}[M]\{1\}}{\{\phi\}^{T}[M]\{\phi\}},
\end{aligned}
$$

where $M$ represents the mass matrix, $K$ represents the lateral stiffness matrix, $C$ represents the damping matrix corresponding to the linear VFDs, and $\{\phi\}$ represents the first vibration mode of the structure. 


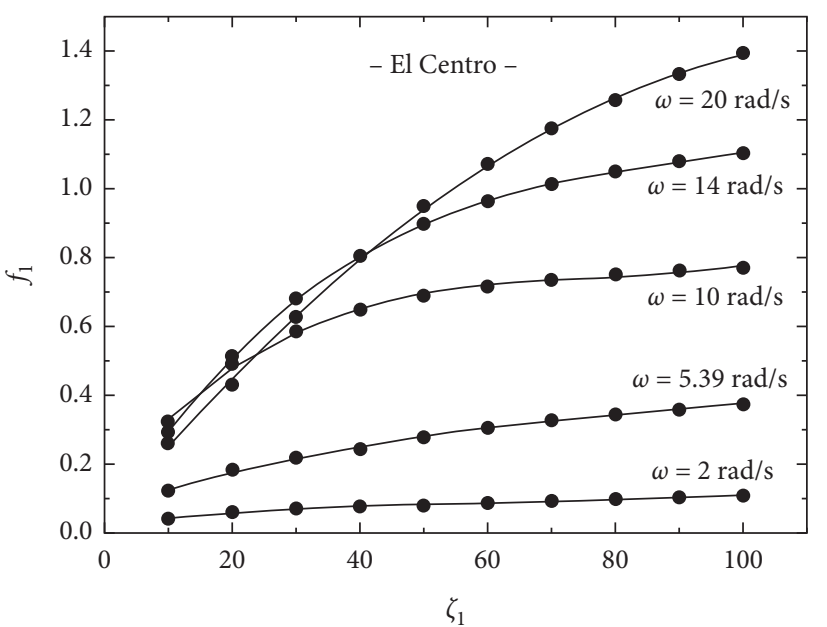

- Numerical point

- Fitting curve

Figure 10: Relationship between $f_{1}$ and $\zeta_{1}$ under El Centro seismic excitation.

TABle 1: Fitting coefficients of the polynomial for different $\omega$ values.

\begin{tabular}{lcccc}
\hline$\omega(\mathrm{rad} / \mathrm{s})$ & \multicolumn{4}{c}{ Fitting coefficients } \\
& $b_{1}$ & $b_{2}$ & $b_{3}$ & $b_{4}$ \\
\hline 2 & 0.23 & -0.42 & 0.30 & 0.01 \\
4 & 0.34 & -0.86 & 0.80 & 0.01 \\
5.39 & 0.40 & -0.89 & 0.84 & 0.04 \\
8 & 1.11 & -2.39 & 1.81 & 0.04 \\
10 & 1.76 & -3.70 & 2.66 & 0.07 \\
12 & 1.84 & -3.99 & 3.04 & 0.08 \\
14 & 1.19 & -3.13 & 3.02 & 0.02 \\
16 & 0.50 & -2.00 & 2.73 & 0.00 \\
18 & 0.14 & -1.28 & 2.44 & 0.01 \\
20 & -0.05 & -0.86 & 2.27 & 0.03 \\
\hline
\end{tabular}

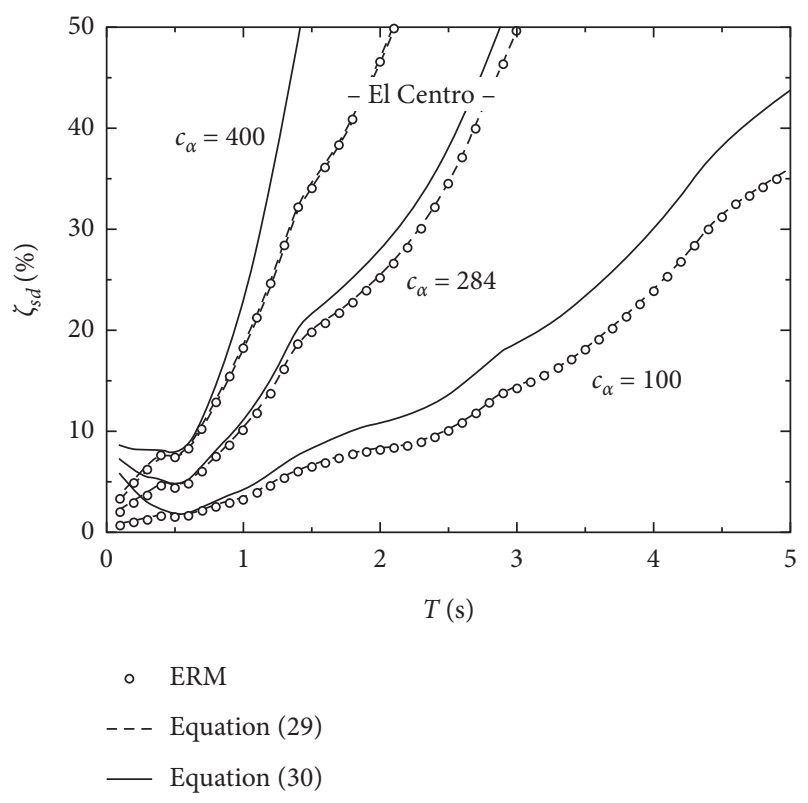

FIGURE 11: ADR spectra with different values of $c_{a}(\mathrm{kN} \cdot \mathrm{s} / \mathrm{m})$ for the El Centro ground motion $(\alpha=0.50)$.

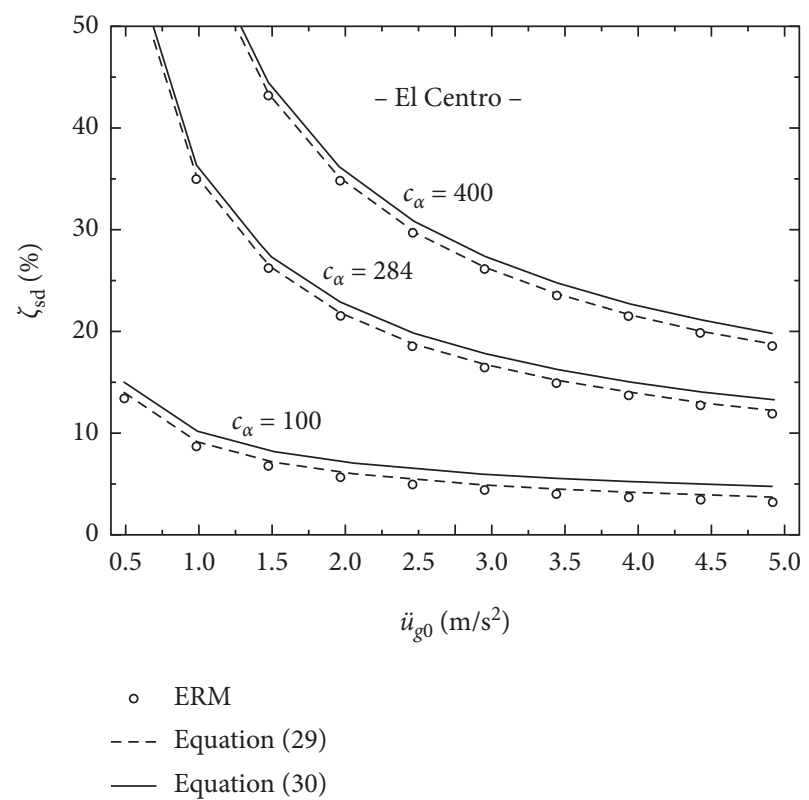

FIGURE 12: Relationship between the ADR and the seismic-excitation peak acceleration with different values of $c_{a}(\mathrm{kN} \cdot \mathrm{s} / \mathrm{m})$ for the El Centro ground motion $(\alpha=0.50)$.

According to equation (33), the equivalent mass is $M^{r}=3.32 \times 105 \mathrm{~kg}$, the equivalent rigidity is $K^{r}=9.64 \times 106 \mathrm{~N} / \mathrm{m}$, and the equivalent damping is $C^{r}=6.08 \times 105(\mathrm{~N} \mathrm{~s} / \mathrm{m})$. Additionally, the equivalent period of the structure is $T=1.1656 \mathrm{~s}$, which is consistent with that of the original frame.

The information of 10 ground motions selected from the Pacific Earthquake Engineering Research Center (PEER), as well as the corresponding average frequency $\Omega_{m}$, is presented in Table 2. The PGA of each ground motion was taken as $500 \mathrm{Gal}$, which is similar to the intensity of a rare 8-degree earthquake, for the time-history analyses. Figure 14 shows the interstory displacement of the shear frame equipped with linear VFDs subjected to the seismic excitation. Clearly, the displacement response of the frame structure tended to be larger under seismic motions with a lower average frequency $\Omega_{m}$.

When $\alpha=1$, the ADR of the linear viscous dampers is calculated as follows using equation (21): $\zeta_{1}=C^{r} /\left(2 M^{r} \omega\right)$ $=C^{r} T / 4 \pi M^{r}=17.00 \%$. The calculation results of the timehistory analyses are presented in Table 2, which are close to $17.00 \%$, indicating that the calculation result of equation (28) can be used to quickly evaluate the ADR with consideration of the resonance condition, despite the error.

When $\alpha \neq 1, \Omega=\omega$ is set; then, equation (6) is transformed into

$$
c_{1}=\frac{\lambda}{\pi} \frac{c_{\alpha}}{\left(\omega u_{o}\right)^{1-\alpha}} .
$$

The nonlinear damping exponent is set as $\alpha=0.5$, and the peak deformation is set as $u_{0}=0.05 \mathrm{~m}$, which is approximately $1 / 60$ of the floor height $(3 \mathrm{~m})$. This is close to the interstory displacement limit for a structure under rare 


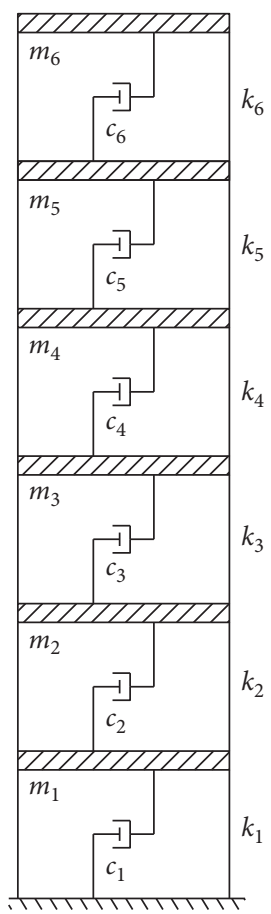

FIgURE 13: Six-story shearing frame model with VFDs.

TABLE 2: Information on the considered earthquake records.

\begin{tabular}{lccccccc}
\hline Name & Location & Year & $M_{s}$ & Station & PGA $(\mathrm{g})$ & $\Omega_{m}$ & $\zeta_{\text {sd }}(\alpha=1)$ \\
\hline KEAT & Kern County & 1952 & 7.4 & Athenaeum & 0.048 & 6.81 \\
SATI & Northridge & 1966 & 6.7 & Saticoy & 0.341 & 7.97 & 14.06 \\
KEHO & Kern County & 1952 & 7.4 & Hollywood & 0.042 & 8.34 & 14.15 \\
NEWH & Northridge & 1994 & 6.4 & Newhall & 0.590 & 9.00 & 15.52 \\
ELCE & Imperial Valley & 1940 & 7.0 & El Centro & 0.348 & 11.20 \\
TAFT & Kern County & 1952 & 7.4 & Taft & 0.159 & 11.22 \\
TABA & Tabas & 1978 & 7.4 & Tabas & 0.854 & 12.16 \\
IRAR & Irpinia & 1980 & 6.9 & Arienzo & 0.027 & 12.99 \\
IRAU & Irpinia & 1980 & 6.9 & Auletta & 0.055 & 18.97 \\
MACO & Mammoth & 1980 & 5.7 & Convict Creek & 0.178 & 17.96 \\
\hline
\end{tabular}

earthquakes based on the Chinese seismic code [35]. The other parameters are identical to those of the original structure. According to equation (34), the equivalent damping coefficient is $c_{a}=2.84 \times 105(\mathrm{~N} \mathrm{~s} / \mathrm{m})$.

Taking the El Centro seismic record of the Imperial Valley earthquake as an example, according to equations (31) and (32), the average period is $T_{m}=0.56 \mathrm{~s}$ and $\Omega_{m}=11.20 \mathrm{rad} / \mathrm{s}$. According to the fitting results in Table 1, $f_{1}$ in equation (29) can be expressed as follows:

$$
f_{1}=0.4 \zeta_{\text {sd,res }}^{3}-0.9 \zeta_{\text {sd,res }}^{2}+0.84 \zeta_{\text {sd,res }}+0.04 \text {. }
$$

By solving equation (29), ADR $\zeta_{\text {sd,res }}$ of the shear frame under the structural resonance condition is calculated as 9.74\%. By substituting this value of $\zeta_{\text {sd,res }}$ into equation (30), the ADR under the El Centro seismic excitation considering the spectral characteristics is determined to be $10 \%$. Additionally, the ADR of the nonlinear viscous damper can be determined using Figures 11 and 12 according to the damping coefficient $c_{a}$, natural vibration period of the structure $T$, or PGA $\ddot{u}_{g 0}$ of the El Centro motion.

Taking the 10 input ground motions listed in Table 2 as seismic excitations, the ADRs were calculated using five methods: the ERM, two nonlinear time-history analysis methods (NMA [28] and Code [35] methods), and equations (29) and (30). The results are presented in Table 3, and a comparison of the ADRs calculated using three of the methods with different frequency ratios is presented in Figure 15. As indicated in Table 3, the difference between the results obtained using the ERM and equation (29) under the resonance condition was very small. The results obtained using the NMA method were larger than those obtained using the Code method, indicating that the Code method is relatively conservative with regard to structural safety. The calculation results of equation (30) were larger than those of equation (29), which is consistent with the change law of the ADR under harmonic excitation with a frequency ratio of $>1$ (see Figure 15). Because 


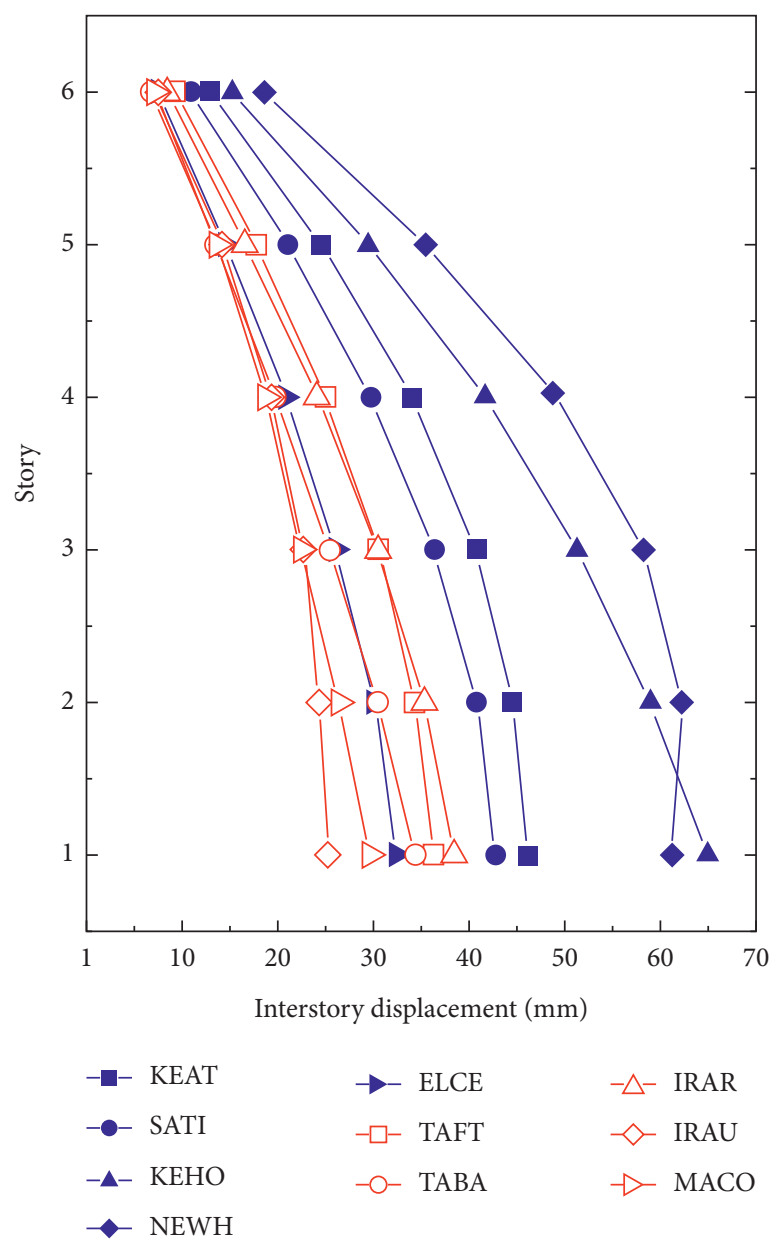

FIGURE 14: Interstory displacement of the six-story shear frame equipped with linear VFDs.

TABLE 3: ADRs calculated using different methods.

\begin{tabular}{|c|c|c|c|c|c|}
\hline \multirow{4}{*}{ Seismic wave } & \multicolumn{5}{|c|}{$\operatorname{ADR}(\%)$} \\
\hline & \multirow{3}{*}{$\begin{array}{c}\Omega_{m}=\omega \\
\text { ERM }\end{array}$} & \multirow{3}{*}{ Equation (29) } & \multicolumn{2}{|c|}{$\Omega_{m} \neq \omega$} & \multirow{3}{*}{ Equation (30) } \\
\hline & & & \multicolumn{2}{|c|}{ Nonlinear time-history analysis method } & \\
\hline & & & NMA [29] & Code method [35] & \\
\hline KEAT & 12.19 & 12.23 & 16.61 & 13.92 & 13.43 \\
\hline SATI & 8.00 & 8.13 & 9.57 & 8.05 & 8.79 \\
\hline KEHO & 12.27 & 12.92 & 15.59 & 14.16 & 13.97 \\
\hline NEWH & 9.32 & 9.78 & 13.52 & 11.59 & 10.32 \\
\hline ELCE & 9.68 & 9.74 & 13.53 & 12.59 & 10.00 . \\
\hline TAFT & 10.39 & 10.68 & 15.25 & 13.77 & 11.74 \\
\hline TABA & 9.66 & 10.05 & 13.95 & 12.30 & 10.52 \\
\hline IRAR & 11.13 & 11.16 & 13.92 & 11.82 & 12.44 \\
\hline IRAU & 13.68 & 13.74 & 18.98 & 15.35 & 15.45 \\
\hline MACO & 13.64 & 14.07 & 16.95 & 14.76 & 15.80 \\
\hline
\end{tabular}

Note. ADR of NMA = (energy dissipated by VFDs/energy dissipated by modal damping $) \times$ inherent structural damping ratio.

the spectral characteristics of the seismic excitation significantly affected the ADR of the damping structure, the calculation results of equation (30), which considered the excitation frequency, were more accurate than those of equation (29).

Figure 16 presents a comparison of the roof-displacement time histories of the shear frame with ADRs calculated using different methods. As shown, the displacement responses calculated using the ERM and equation (30) were similar, and the displacement responses obtained using the Code method were smaller than those for the other two methods, indicating that the proposed calculation method is relatively conservative. 


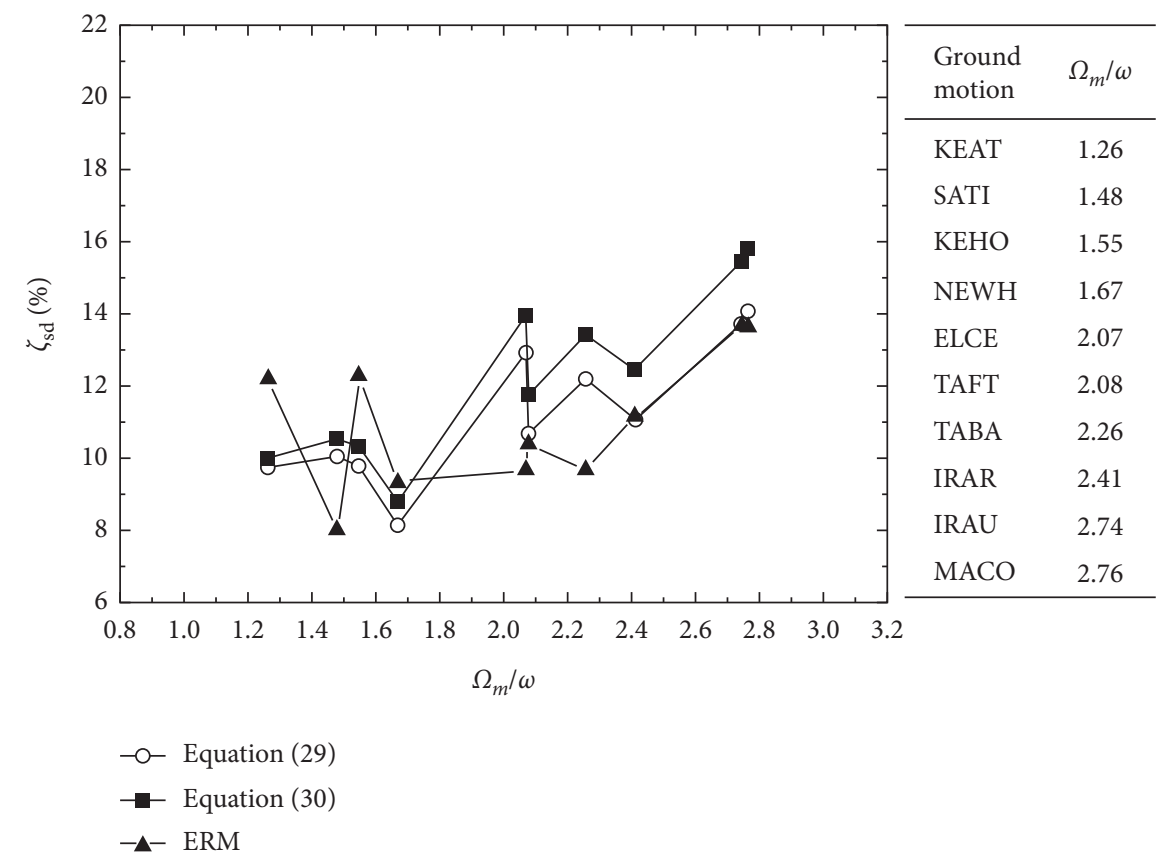

Figure 15: Comparison of the calculation results of equations (29) and (30) and the ERM.

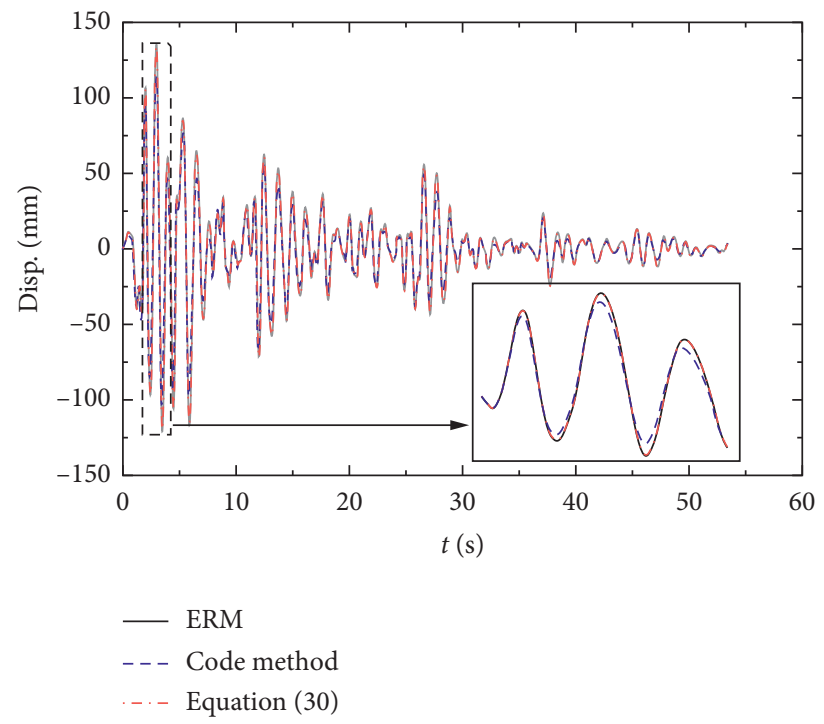

FIGURE 16: Roof-displacement time histories of the shear frame with ADRs calculated using different methods.

\section{Conclusions}

A new simplified calculation method for the ADR of a damping structure equipped with a nonlinear viscous damper was developed on the basis of previous studies. The accuracy of this method was verified by analysing a six-story $\mathrm{RC}$ frame structure. According to the calculation results, the following conclusions are drawn:

(1) The average frequency $\Omega_{m}$ was introduced to characterise the seismic excitation, and the ADR calculated using the proposed method considering the effect of the average frequency was larger than that calculated using the ERM. Moreover, as the earthquake intensity increased, the ADR decreased.

(2) Studying the effect of the excitation frequency on the calculated value of the ADR with different velocity exponents revealed that the ADR of the damping structure was the smallest for $\Omega_{m} / \omega=1$, and it decreased with the increasing frequency ratio for $\Omega_{m} /$ $\omega<1$. Additionally, the ADR of the damping structure decreased with an increase in the seismicexcitation peak acceleration.

(3) According to the case study of a shear frame, the displacement response of the frame structure tends 
to be larger under seismic motions with a lower average frequency $\Omega_{m}$, indicating the significant impact of the frequency characteristics of the seismic excitation on the structural response. Compared with other methods tested, the calculation results of the proposed simplified method were closer to those of the Code method, confirming the effectiveness of the proposed method.

When the ground motion characteristics, structural characteristics, and damper parameters are known, the proposed method can be used to calculate the ADR of the damping structure conveniently. However, the method for calculating the ground motion frequency using the RSAP requires further improvement.

\section{Data Availability}

Some or all data and models used during the study are available from the corresponding author upon request.

\section{Conflicts of Interest}

The authors declare no conflicts of interest.

\section{Acknowledgments}

This research was funded by the National Natural Science Foundation of China (grant nos. 51678301 and 51678302) and the National Key R\&D Program of China (grant no. 2017YFC0703600).

\section{References}

[1] R. D. Bertero and Great, "American earthquakes: lessons for seismic design and construction," Journal of Construction Engineering \& Management, vol. 140, no. 4, Article ID B4013003, 2010.

[2] D. M. Siringoringo and Y. Fujino, "Long-term seismic monitoring of base-isolated building with emphasis on serviceability assessment," Earthquake Engineering \& Structural Dynamics, vol. 44, no. 4, pp. 637-655, 2015.

[3] W. Z. Xu, D. S. Du, S. G. Wang et al., "Shaking table test of multi-dimensional seismic response of long-span gird structure with base-isolation," Engineering Structures, vol. 201, 2019.

[4] O. M. Ramirez, M. C. Constantinou, J. D. Gomez, A. S. Whittaker, and C. Z. Chrysostomou, "Evaluation of simplified methods of analysis of yielding structures with damping systems," Earthquake Spectra, vol. 18, no. 3, pp. 501-530, 2002.

[5] Y. Huang, R. Sturt, and M. Willford, "A damping model for nonlinear dynamic analysis providing uniform damping over a frequency range," Computers \& Structures, vol. 212, pp. 101-109, 2019.

[6] H. Anajafi, R. A. Medina RA, and E. S. Bell, "Effects of the improper modeling of viscous damping on the first-mode and higher-mode dominated responses of base-isolated buildings," Earthquake Engineering \& Structural Dynamics, vol. 49, no. 1, pp. 151-173, 2020.

[7] A. Sarlis and M. C. Constantinou, Modeling Triple Friction Pendulum Isolators in Program SAP2000. Supplement to MCEER Report 05-009, Document Distributed to the
Engineering Community Together with Example Files, University at Buffalo, Buffalo, NY, USA, 2010.

[8] A. Bajric, R. Brincker, and S. Thöns, "Evaluation of damping estimates in the presence of closely spaced modes using operational modal analysis techniques," in Proceedings of the 6th International Operational Modal Analysis Conference, Gijón, Spain, May 2015.

[9] W.-I. Liao, I. Mualla, and C.-H. Loh, "Shaking-table test of a friction-damped frame structure," The Structural Design of Tall and Special Buildings, vol. 13, no. 1, pp. 45-54, 2004.

[10] Y. Liu, C.-L. Wang, and J. Wu, "Development of a new partially restrained energy dissipater: experimental and numerical analyses," Journal of Constructional Steel Research, vol. 147, pp. 367-379, 2018.

[11] H. AmiriA. Ahmadie et al., "Experimental and analytical study of block slit damper," Journal of Constructional Steel Research, vol. 141, pp. 167-178, 2018.

[12] R. H. Zhang and T. T. Soong, "Seismic design of viscoelastic dampers for structural applications," Journal of Structural Engineering, vol. 118, no. 5, pp. 1375-1392, 1992.

[13] Y. Q. Ni, J. M. Ko, and Z. G. Ying, "Random seismic response analysis of adjacent buildings coupled with non-linear hysteretic dampers," Journal of Sound and Vibration, vol. 246, no. 3, pp. 403-417, 2001.

[14] F. C. Ponzo, A. Di Cesare, D. Nigro et al., "Jet-pacs project: dynamic experimental tests and numerical results obtained for a steel frame equipped with hysteretic damped chevron braces," Journal of Earthquake Engineering, vol. 16, no. 5, pp. 662-685, 2012.

[15] C.-L. Wang, Y. Liu, X. Zheng, and J. Wu, "Experimental investigation of a precast concrete connection with all-steel bamboo-shaped energy dissipaters," Engineering Structures, vol. 178, pp. 298-308, 2019.

[16] Y. Ribakov and A. N. Dancygier, "High-efficiency amplifiers for viscous damped structures subjected to strong earthquakes," Structural Design Tall Special Buildings, vol. 15, no. 2, pp. 221-232, 2016.

[17] X. L. Wu, W. Guo, P. Hu et al., "Seismic performance evaluation of building-damper system under near-fault earthquake," Shock \& Vibration, vol. 2020, Article ID 2763709, 2020.

[18] S.-H. Lee, K.-W. Min, J.-S. Hwang, and J. Kim, "Evaluation of equivalent damping ratio of a structure with added dampers," Engineering Structures, vol. 26, no. 3, pp. 335-346, 2004.

[19] F. A. Charney and R. J. McNamara, "Comparison of methods for computing equivalent viscous damping ratios of structures with added viscous damping," Journal of Structural Engineering, vol. 134, no. 1, pp. 32-44, 2008.

[20] A. Occhiuzzi, "Additional viscous dampers for civil structures: analysis of design methods based on effective evaluation of modal damping ratios," Engineering Structures, vol. 31, no. 5, pp. 1093-1101, 2009.

[21] S. Silvestri, G. Gasparini, and T. Trombetti, "A five-step procedure for the dimensioning of viscous dampers to be inserted in building structures," Journal of Earthquake Engineering, vol. 14, no. 3, pp. 417-447, 2010.

[22] M. Palermo, S. Silvestri, G. Gasparini, and T. Trombetti, “A direct five-step procedure for the dimensioning of viscous dampers to Be inserted in frame structures," Applied Mechanics and Materials, vol. 847, pp. 233-239, 2016.

[23] M. Palermo, S. Silvestri, G. Gasparini, A. Dib, and T. Trombetti, "A direct design procedure for frame structures with added viscous dampers for the mitigation of earthquake- 
induced vibrations," Procedia Engineering, vol. 199, pp. 1755-1760, 2017.

[24] P. P. Diotallevi, L. Landi, and A. Dellavalle, "A methodology for the direct assessment of the damping ratio of structures equipped with nonlinear viscous dampers," Journal of Earthquake Engineering, vol. 16, no. 3, pp. 350-373, 2012.

[25] D. G. Weng, C. Zhang, X. L. Lu, S. Zeng, and S. M. Zhang, "A simplified design procedure for seismic retrofit of earthquakedamaged RC frames with viscous dampers," Structural Engineering and Mechanics, vol. 44, no. 5, pp. 611-631, 2012.

[26] L. Landi, S. Lucchi, and P. P. Diotallevi, "A procedure for the direct determination of the required supplemental damping for the seismic retrofit with viscous dampers," Engineering Structures, vol. 71, pp. 137-149, 2014.

[27] F. N. Kudu, Ş. Uçak, G. Osmancikli, T. Türker, and A. Bayraktar, "Estimation of damping ratios of steel structures by operational modal analysis method," Journal of Constructional Steel Research, vol. 112, pp. 61-68, 2015.

[28] S. Ishimaru and C. Kuo, "New version/ductility factor control method," Journal of Structural and Construction Engineering (Transactions of AIJ), vol. 80, no. 708, pp. 241-251, 2015.

[29] D. G. Wen, C. Li, X. Y. Hu et al., "Calculation of additional effective damping ratio of damping structure based on modal damping energy consumption," Journal of Civil Engineering, vol. 49, pp. 19-24, 2016.

[30] L. Landi, C. Vorabbi, O. Fabbri, and P. P. Diotallevi, "Simplified probabilistic seismic assessment of RC frames with added viscous dampers," Soil Dynamics and Earthquake Engineering, vol. 97, pp. 277-288, 2017.

[31] J. S. Love and M. J. Tait, "Estimating the added effective damping of SDOF systems incorporating multiple dynamic vibration absorbers with nonlinear damping," Engineering Structures, vol. 130, pp. 154-161, 2016.

[32] Y. He, Y. Xiao, Y. Liu, and Z. Zhang, "An efficient finite element method for computing modal damping of laminated composites: theory and experiment," Composite Structures, vol. 184, pp. 728-741, 2018.

[33] A. K. Chopra, Dynamics of Structures: Theory and Applications to Earthquake Engineering,pp. 66-103, Prentice-Hall, Upper Saddle River, NJ, USA, 2nd ed. edition, 2001.

[34] I. Takewaki, "Optimal damper placement for minimum transfer functions," Earthquake Engineering \& Structural Dynamics, vol. 26, no. 11, pp. 1113-1124, 1997.

[35] GB 50011-2010, Code for Seismic Design of Buildings, China Architecture and Industry Press, Beijing. China, 2010. 